\title{
ODDAŁBYM CI MOJE SERCE - OD NUMERU PASZPORTU DO AUTOKREACJI KULTUROWO UWARUNKOWANE WZORCE MĘSKOŚCI I GRY Z KONWENCJĄ W CYKLU I WOULD GIVE YOU MY HEART ROZMOWA Z KRZYSZTOFEM MARCHLAKIEM
}

Elżbieta Wiącek: W roku 2018 rozpocząłeś prace nad serią fotografii I would give you my heart, która jest formą komentarza na temat pozycji osób ze społeczności LGBTQ we współczesnym świecie. Projekt jest ciągle uzupełniany o kolejne realizacje. Seria prezentowana była między innymi w magazynie dla fotografów "NAF”, w galerii Off Frame w Krakowie w 2019 roku przez The Little Black Gallery w Londynie w ramach projektu Boys Boys Boys. Każdy z modeli na zdjęciach trzyma w ręce swój paszport. Dokument ten wydaje się niemal idealnym symbolem narzuconej identyfikacji. Przypadkowy numer i przypisanie do tożsamości narodowej, której nie wybieramy, mocno kontrastuje tu z kreacją prawie nagich ciał - posypanych brokatem, udekorowanych koronkowymi kołnierzami lub biżuterią i malarsko oświetlonych jak w dawnych obrazach albo na fotografiach Davida LaChapelle'a... Czy możesz wskazać na jakieś impulsy, które przyczyniły się do powstania tej serii? Czy to była czyjaś historia, czy to było jakieś zdjęcie prasowe, czy może jakaś migawka telewizyjna albo obraz malarski, albo w ogóle jakaś kompilacja tych bodźców?

Krzysztof Marchlak: Zdecydowanie była to kompilacja tych elementów. Zacznijmy może od tego, że była to pierwsza seria fotograficzna, którą zrealizowałem. Do tej pory zajmowałem się głównie malarstwem i nie miałem żadnego doświadczenia $w$ medium fotograficznym. $W$ trakcie pracy nad tą serią nabywałem nową umiejętność oglądania świata przez obiektyw aparatu, którą rozwijam do dziś. Pierwszym zdjęciem, które rozpoczęło tę 
przygodę, był wykonany dość spontanicznie autoportret z paszportem. Powstał on w nocy, niedługo po moim powrocie ze Stanów Zjednoczonych. Jako dziecko lat 90. pamiętam, jak dużym marzeniem dla wielu Polaków było wygranie zielonej karty - przepustki do Dreamland... Ten „perfekcyjny" kraj oglądałem również w filmach, gdzie - głównie w dużych produkcjach hollywoodzkich - zaczęto pokazywać związki homoseksualne lub zaczęli pojawiać się bohaterowie geje. Zresztą też pamiętam końcówkę lat 90., kiedy to również w polskich serialach pojawiały się pierwsze osoby homoseksualne.

E.W.: Pamiętasz może tytuły tych seriali albo filmów?

K.M.: Były to seriale, które oglądała moja rodzina dla zabicia czasu, polskiej produkcji, tytułów nie pamiętam.

E.W.: ...czego nie było w polskich produkcjach, po prostu.

K.M.: Pamiętam też taką sytuację jako młody chłopiec. Pojawiła się opowieść o gejach w telewizji w serialu Doktor Quinn, przy którym spotykała się cała rodzina. Zapytałem się wtedy mamy: "Mamo, co to znaczy gej?”. A ona powiedziała mi, że to jest, jak mężczyzna kocha mężczyznę.

E.W.: A który to był rok, mniej więcej, pamiętasz? Tak mniej więcej.

K.M.: Wiesz co, nie pamiętam dokładnie, miałem wtedy może 10-12 lat. Jakoś tak. Po uzyskaniu odpowiedzi już o to więcej nie pytałem. Dziwnie zainteresowałem się tym jednak. Później, kiedy moja seksualna tożsamość zaczęła się kształtować, przypomniały mi się te słowa i ta krótka rozmowa. Wracając jednak do samych zdjęć, pamiętam lata 90. i marzenie o Stanach Zjednoczonych jako „kraju wolności”, gdzie można spełniać marzenia. Jako dorosły mężczyzna pojechałem tam i sprawdziłem. Moją pierwszą podróżą za ocean było Miami, jednak zwiedziliśmy również peryferia i całą Florydę. Pamiętam stamtąd wielki billboard, na którym było napisane: „America love it or leave it". Poczułem się trochę zagrożony, może nie do końca zagrożony, ale, jakby to powiedzieć...

E.W.: ...że ten kraj stawia ci pewne warunki, prawda? Że musisz go w całości zaakceptować. 
K.M.: Tak. I że ta wolność obiecywana mi w złudzeniach filmowych jest pewną bańką.

E.W.: A który był to rok, kiedy poleciałeś do Miami?

K.M.: Wiesz co... To był... Zaraz, zaraz... To było chyba z osiem lat temu może. Doświadczenie to zostało mi w głowie na lata. Niedługo później po raz kolejny byłem w USA, tym razem w Nowym Jorku, i właściwie zdjęcie, o którym tyle mówię, pojawiło się po tym wyjeździe, kiedy zacząłem poznawać inny obraz Stanów Zjednoczonych - ten, który mi się podoba. Wtedy też kupiłem sobie mój pierwszy aparat. Po powrocie zobaczyłem leżący na stole w mieszkaniu paszport, w którym była wiza, czyli taka przepustka do „lepszego świata”, do posmakowania go. Miałem w domu jeszcze takie plastikowe zabezpieczenia do butelek $z$ winem z lotniska. Zupełnie spontanicznie założyłem je na szyję, na ręce, rozebrałem się, zrobiłem zdjęcie z paszportem, który zasłaniał moje przyrodzenie.

E.W.: Czyli był to właściwie bardzo osobisty początek?

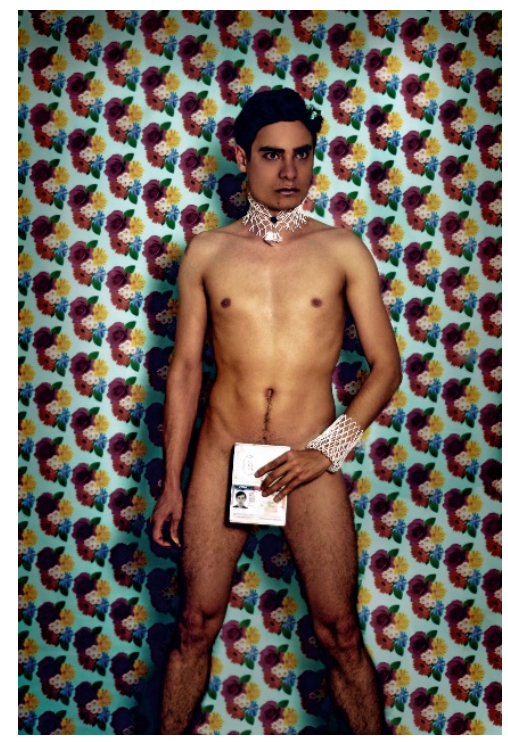

Z serii I would give you my heart, fotografia cyfrowa, 2018/2020; autor: Krzysztof Marchlak 
K.M.: Tak. Do zdjęcia zbudowałem jeszcze scenografię, tapetę. Miałem dużo papieru o kwiecistym wzorze do pakowania prezentów, który przykleiłem do ściany. Zrobiłem zdjęcie i stwierdziłem... fajne, podoba się. Był w nim zawarty pewien ładunek emocjonalny. Chciałem kontynuować ten pomysł jako serię, ale stwierdziłem, że moja historia jest tylko jedną z wielu i postanowiłem otworzyć się na współpracę z innymi modelami. Zacząłem więc pomału zapraszać inne osoby na sesje zdjęciowe. Na początku byli to znajomi, którzy chętnie wzięli udział w tym przedsięwzięciu, lecz później przerodziło się to w projekt mocno obecny w social media, a zwłaszcza na Instagramie. Jeszcze odnośnie do inspiracji - razem z przyjaciółką słuchaliśmy utworu Go West Village People, który właściwie opowiada o bezpiecznym miejscu dla osób LGBT, o San Francisco. Zauważyliśmy z rozbawieniem, że o dziwo ta sama linia melodyczna została przechwycona przez polskich kibiców do piosenki Polska, biało-czerwoni... Myślę więc sobie: środowisko, które jest uznawane za bardziej nietolerancyjne, przechwytuje pewną linię melodyczną z utworu, który...

E.W.: ...ma korzenie w kulturze gejowskiej. Ciekawe...

K.M.: Dokładnie.

E.W.: Takie proste pytanie, ale myślę, że może być dobrym punktem wyjścia: Dlaczego twoi modele są niemal nadzy? Pytając o to, zakładam, że ubranie jest takim komunikatem społecznym, który mówi dużo o człowieku. Ciało oczywiście też, ale inaczej. Natomiast jeśli chodzi o zakorzenienie w społeczeństwie, to ubranie jest tu chyba takim wyraźniejszym komunikatem. Czy postrzegasz może ciało jako taki ekran do projekcji naszych wyobrażeń o tych mężczyznach? Czy ciało jest czymś bardziej neutralnym niż ubranie?

K.M.: Nagość jest jak zrzucenie zbroi. Ubranie nas kreuje. Ubranie sprawia, że jesteśmy $w$ jakiś sterowany przez nas sposób odbierani przez społeczeństwo. Wybieramy na przykład kolory, które mają coś podkreślić albo uwewnętrznić nasz charakter czy osobowość. Natomiast ciało, które samo w sobie jest piękne, pozbawione tej - jak to nazwałem - „zbroi”, jest bardzo delikatne, wrażliwe na wzrok innych. $Z$ drugiej strony, nasz wizerunek staje się bardziej szczery, gdyż bez odzieży nie mamy nic do ukrycia. $Z$ tego powodu na moich zdjęciach postacie pozbawione są codziennego ubioru. Nagość jest w nich częściowo zakryta i jest podana odbiorcy w taki sposób, 
który według mnie jest wystarczający do przekazania głównej myśli obrazu. Cechą charakterystyczną serii zdjęć I would give you my heart jest wyraźne bazowanie na schemacie wizualnym: mamy zawsze centralnie ustawioną postać, rozebraną, zawsze zasłoniętą, z ozdobą na szyi i na dłoni. Właściwie tym, co różni każde ze zdjęć, jest indywidualna zewnętrzność bohaterów. Siła tych zdjęć polega na ich zestawieniu i wzajemnym na siebie oddziaływaniu. Jedno zdjęcie nie działa tak jak dziesięć czy dwadzieścia. Zależy też mi na tym, aby ciało przeze mnie ukazywane nie było erotyczne czy pornograficzne, zdecydowanie bliższa jest mi jego auratyczna natura, bardziej sensualna, delikatna. Zestawienie delikatnego ciała podatnego na uszkodzenia ze wzrokiem, spojrzeniem, które...

E.W.: ...tak, bo to jest najczęściej to spojrzenie w kamerę, tak naprawdę...

K.M.: ...dokładnie tak. Spojrzenie w kamerę, silne, bezpośrednie, bezbronne. Ono, przynajmniej dla mnie, buduje pewien dysonans poznawczy. Siła kontra delikatność, kolejna opozycja to konkretny dokument tożsamości kontra świat wyobrażony. Piękna ozdoba na szyi, która z drugiej strony, może oznaczać również obrożę? Budując nastrój tych fotografii, zależy mi na tym, żeby tworzyć go na zasadzie kontrastu, trochę jak ze światłem i cieniem w naturze.

Zwykli ludzie, a nie profesjonalni modele, którzy zgłosili się do udziału w projekcie, są osobami o różnych fizjonomiach, o różnym ciele, mniejsi, więksi, szczuplejsi, naturalni. Każde z tych ciał jest piękne na swój wyjątkowy sposób i nie mówię tego kokieteryjnie. Dla mnie każde z nich ma w sobie pewien ładunek emocjonalny, światło, które ja staram się wydobyć.

Wracając na chwilę do tematu z początku rozmowy o wyjazdach. Mam to szczęście, że mogę dużo podróżować i czerpać albo przygodnie skorzystać $z$ atrakcji różnych miejsc i spotykać różnych ludzi, rozmawiać z nimi o problemach związanych z tolerancją i o radościach dnia codziennego. W trakcie tych eskapad okazuje się, że właściwie o takim stuprocentowym sukcesie w szukaniu własnego miejsca, gdzie po prostu jest nam dobrze, możemy zapomnieć. Oczywiście są miejsca, które dają pewną wolność, większą lub mniejszą, jednak ideał jest tylko w naszej głowie. Nasze dążenie do tego, aby prawa człowieka i mniejszości były wszędzie jak najbardziej zbliżone, liberalne i oparte na idei wolności, powinno ciągle być kluczowym celem działań społecznych i ważne, aby sztuka również w takie działania się włączała. Doświadczając różnych obszarów geograficznych, różnych miejsc, 


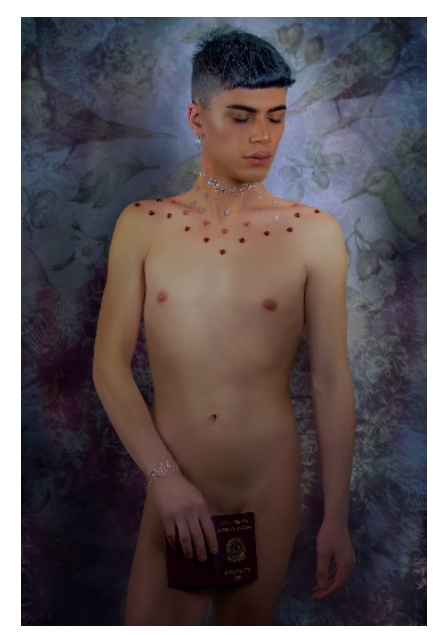

$Z$ serii I would give you my heart, fotografia cyfrowa, 2018/2020; autor: Krzysztof Marchlak

przebywając z różnymi ludźmi, wydaje mi się, że takie miejsce nie istnieje. Może jestem w błędzie. Chętnie chciałbym być w błędzie...

E.W.: Czy w tej serii pojawia się estetyka Instagramu albo jakiś kanon piękna? Powiedzmy, biorąc pod uwagę starogreckie słowo kalon, czyli - jak zauważa Umberto Eco - „jest kalon, co się podoba, co budzi podziw, co przyciąga spojrzenie".

K.M.: Tak i nie. To znaczy Instagram jest to przestrzeń, która komunikuje treści głównie obrazem i hasztagiem. Hasztag odsyła nas zawsze do konkretnego obrazu. Kiedy przyjrzymy się działaniem influencerskim na przykład albo osobom, które zajmują się modelingiem czy promowaniem produktu, to ich konto na Instagramie jest prowadzone bardzo spójnie. Jeden z moich modeli działa dużo w make-upie i w kosmetologii, i jego Instagram jest bardzo konsekwentnie prowadzony: twarz, make-up, lokowanie produktu, wideo z tutorialem dotyczącym wykonania makijażu, komentarze dotyczące tematów równouprawnienia. Wydaje mi się, że Instagram jest dobrą przestrzenią na pokazywanie sztuki i prowadzenie projektów. Moja seria zaistniała właśnie dzięki Instagramowi. To stąd pozyskiwałem kolejnych modeli. W promowaniu malarstwa za pośrednictwem tego narzędzia sytuacja wygląda trochę inaczej... 
E.W.: Czyli jednak media społecznościowe są wybitnie fotograficzne?

K.M.: Medium malarskie wymaga bezpośredniego kontaktu z obiektem sztuki i nie da się tego zastąpić nawet najlepszą reprodukcją. Instagram daje możliwość promowania własnej widoczności, działań i przede wszystkim samego siebie. Cała kultura selfie na tym właśnie się opiera - nacelowanie działań i uwagi na ,ja”. Autokreacja w tym przypadku jest bardzo szybka, przygodna i musi złapać oko odbiorcy, aby go zatrzymać. Dlatego na przykład dwóch moich znajomych instagramerów ze zdjęć zaczęło przechodzić w aktywność wykorzystującą krótkie filmiki, bo one zatrzymywały odbiorcę na dłużej. Rozmawiałem z osobami, które mają powyżej 20 tysięcy obserwujących, i właśnie one powiedziały mi, że ostatnio jakieś algorytmy aplikacji są tak zmienione, że film ma obecnie większe zasięgi.

\section{E.W.: Ciekawe.}

K.M.: Zauważyłem też, że jednym z elementów, które przyciągają odbiorców, jest nagość. Dlaczego? Czy tak naprawdę właśnie ona zatrzyma przeciętnego odbiorcę najbardziej? Nie wiem, to są takie pytania, które sam sobie zadaję.

E.W.: Tak, nie ma na to takiej łatwej odpowiedzi.

K.M.: To wszystko pokazuje też, dlaczego na przykład malarstwo w tym przypadku jest trudnym materiałem do zaistnienia w sieci. Przekaz malarski wymaga koncentracji, przyjrzenia się, poznania, „wejścia” w obraz. Wymaga to czasu i skupienia.

E.W.: W przypadku malarstwa struktura powierzchni czasem też działa na odbiorcę, rozmiar obrazu...

K.M.: ...dokładnie. W działaniach stricte instagramowych interakcja z obrazem to jest pewnie jakaś sekunda lub jej ułamek. Jeżeli zdjęcie jest mało szczegółowe, to mogę "ogarnąć” je w tak krótkim czasie. Nie wiem, ile sekund średnio użytkownik ogląda jedno zdjęcie, jednak musi być w nim coś, co go zatrzyma. Wydaje mi się, że „kanon” piękna Instagramu, poza nienaturalnością scen i osób uzyskiwaną głównie za pomocą filtrów kolorystycznych, to przede wszystkim prowokacja, która musi wywoływać 
emocje - pozytywne czy negatywne, szok, radość, odczucie piękna. Musi być w zdjęciu to coś. Zwykła fotografia raczej nikogo nie zainteresuje. Po tym trochę długim wywodzie dochodzę do wniosku, że moje zdjęcia nie do końca wiążą się z estetyką czy - jak to nazwałaś - „kanonem” instagramowym, ponieważ ich finalną wersją jest wydruk dużego formatu, a nie szybkie doznanie wizualne cyfrowej jakości. Zasoby tego medium wykorzystuję jednak do działań zmierzających do powstania fotografii $w$ fazie projektowej związanej z pozyskiwaniem modeli oraz do promocji własnej twórczości.

E.W.: Dziękuję. Jeszcze bym zapytała o internet. Czy twoim zdaniem jego rola się zwiększa w ogóle w stosunkach międzyludzkich? Czy jednocześnie intensyfikuje ten proces globalizacja? Czy możliwość korzystania z internetu i globalizacja stanowią sprzężenie zwrotne, bo te procesy nawzajem się intensyfikują i wspomagają? Moim zdaniem przestrzeń międzykulturowa poprzez te dwa procesy ma coraz częściej wymiar wirtualny, ponieważ nie musi się wiązać z podróżą. Abstrahując już od kwestii performatywności płci, dziewczyna mieszkająca na przykład na północy Polski, w jakimś małym miasteczku, może być miłośniczką mangi japońskiej i jej indywidualna tożsamość czy wewnętrzny świat będą przez tę fascynację transkulturowe. Przestrzeń międzykulturowa ma coraz silniejszy wymiar medialny. Czy twoim zdaniem ta sytuacja zwiększa różnorodność możliwości wyboru, jeśli chodzi o prezentację swojej płciowości oraz orientacji seksualnej?

K.M.: Wydaje mi się, że absolutnie tak. Z prostego względu - działania w social media nastawione są na reakcję odbiorcy na wykreowany przez nas wizerunek lub temat. Kiedy jest duże zainteresowanie naszą działalnością, to z pewnością wpływa to pozytywnie na właściciela tego konta, prawda? Sprawia, że nie czujemy się sami.

E.W.: Taka afirmacja ze strony innych osób.

K.M.: Tak. Ja sam pochodzę z bardzo małej miejscowości, w latach 90. i pierwszej dekadzie XXI wieku miałem poczucie osamotnienia w swojej indywidualności. Było to trudne i deprymujące. Czujemy się ograniczeni, bo jesteśmy sami...

E.W.: ...dlaczego jestem „inny”? Czy jest ktoś taki jak ja, prawda? Takie pytania... 
K.M.: Internet pozwala nam spotykać osobę podobną. Ale też sobie myślę, że jest to także znakomity obszar do budowania koneksji artystycznych, współpracy. Tak jak mówiłem, moi modele skontaktowali się ze mną właśnie przez internet.

E.W.: ...czyli pewien network tak naprawdę się wytwarza.

K.M.: Nawiązałem też współpracę z niektórymi galeriami właśnie za pośrednictwem tego narzędzia. Zdarza mi się również bezpośrednio napisać do jakiegoś artysty albo celebryty, który mnie interesuje, i dostać odpowiedź. Jednym z moich modeli była osoba niebinarna z Londynu, do której napisałem, że podoba mi się jej profil. Dostałem szybko odpowiedź z propozycją współpracy. Tak się złożyło, że dwa tygodnie później miałem być w Londynie $z$ innych powodów. Spotkaliśmy się więc, zrobiliśmy zdjęcia i do dzisiaj jesteśmy przyjaciółmi. Doświadczenie to pokazało mi, że kontakt przez internet może przerodzić się w kontakt bezpośredni i współpracę, która czymś zaowocuje. A jeżeli pojawia się owoc, to też pojawia się satysfakcja.

\section{E.W.: Dziękuję za rozmowę!}

Krzysztof Marchlak (ur. 1987) - malarz, fotograf, twórca instalacji artystycznych mieszkający w Krakowie i Mediolanie. Tytuł doktora sztuki uzyskał na krakowskiej ASP w 2018 roku. Wcześniej ukończył studia drugiego stopnia na Wydziale Malarstwa tejże uczelni (2012). Pracuje na stanowisku adiunkta w Instytucie Malarstwa i Edukacji Artystycznej na Wydziale Sztuki UP w Krakowie. Jest autorem kilku wystaw indywidulanych oraz uczestnikiem ponad 40 pokazów zbiorowych w Polsce i za granicą. Jego twórczość oscyluje wokół zagadnień tożsamości indywidualnej oraz surrealistycznych wizji przyszłości. W 2018 roku rozpoczął prace nad serią fotografii I would give you my heart, która jest formą komentarza na temat pozycji osób ze środowiska LGBTQ we współczesnym świecie. Projekt jest ciągle uzupełniany o kolejne realizacje.

Link do strony www: https://marchlak.wixsite.com/marchlak/go-west-series 